\title{
Relationship between Willingness to Communicate in English and Foreign Language Enjoyment
}

\author{
Yin Kun*, Fatiha Senom, Chew Fong Peng \\ Department of Language and Literacy Education, University of Malaya, Malaysia
}

Received March 15, 2019; Revised July 15, 2020; Accepted July 29, 2020

\section{Cite This Paper in the following Citation Styles}

(a): [1] Yin Kun, Fatiha Senom, Chew Fong Peng , "Relationship Between Willingness to Communicate in English and Foreign Language Enjoyment," Universal Journal of Educational Research, Vol. 8, No. 10, pp. 4853 - 4862, 2020. DOI: 10.13189/ujer.2020.081057.

(b): Yin Kun, Fatiha Senom, Chew Fong Peng (2020). Relationship Between Willingness to Communicate in English and Foreign Language Enjoyment. Universal Journal of Educational Research, 8(10), 4853 - 4862. DOI: 10.13189/ujer.2020.081057.

Copyright $\subseteq 2020$ by authors, all rights reserved. Authors agree that this article remains permanently open access under the terms of the Creative Commons Attribution License 4.0 International License

\begin{abstract}
This research sets out to investigate the relationship between WTC (willingness to communicate) in English and FLE (Foreign Language Enjoyment) among Chinese EFL (English as a foreign language) learners in normal universities in Shandong Province, China. This is a quantitative research through survey technique via a questionnaire on students' demographic variables, WTC, and FLE. The data collected from 128 recruited students have been addressed by SPSS (Statistical Package for Social Science) and AMOS (Analysis of Moment Structures). The outcomes of this research show that the tertiary EFL students in Shandong normal universities evaluated themselves as taking a high level of FLE and L2 WTC. Besides, data exhibited there was a significant positive relationship that is moderately strong between FLE and L2 WTC. Furthermore, the multiple regression analysis showed that FLE-teacher is the FLE dimension that significantly impacts on L2 WTC. Through the achievement of the fitness indexes required for GFI (Goodness of Fit Index), Ratio Chisq/df (Chi-square/ Degrees of Freedom), and RMR (Root Mean Square) at an acceptable level, the proposed structural model does fit with the data gathered. Thereby, the structural model proposed based on the conceptual framework was established for this study.
\end{abstract}

Keywords Willingness to Communicate in English, EFL, Foreign Language Enjoyment, Education, Positive Psychology

\section{Introduction}

\subsection{Background of L2 WTC in English}

TEFOL (Teaching English to Speakers of Other Languages) has taken on a wide range of reform and alteration during the last century. Previously, TEFOL highlighted on the proficiency of linguistic structure, nonetheless, more recently, it has attached much more importance to the language learners' pragmatic language use competence and the actual communicative ability for the goal of realistic communication (Cetinkaya, 2005). CLT (Communicative language teaching) underlines the actual language use for significantly interactive communication in the process of FL (foreign language) acquisition.

Greater care to underscore the communicative uses of foreign or second language have been given by many researchers, such as MacIntyre and Charos (1996). They explicitly proclaimed that one must talk to learn and suggestions for improving linguistic proficiency through using the language were also provided to the language learners. That is to say, L2 learners are not enabled to get proficient unless they communicatively use the target language (Khajavy, Ghonsooly, Hosseini Fatemi, \& Choi, 2016).

Furthermore, aligned with the recent tendency for using the conversational method in foreign language education, the major role of creating a language through the process of interactive communication and language usage has also 
been widely buttressed by second language acquisition (SLA) theories. To illustrate, comprehensible output hypothesis proposed by Swain and Lapkin (1995) and interaction hypothesis argued by Long (1996).

As for the context of China, communicative competency for using English also has been highly accentuated by the educative policy-makers. As clearly pointed out by the Ministry of Education of China, to train the communicative competence and enable Chinese EFL students to proficiently speak in English in the future life of learning, working, and social interaction are considered as one of the crucial goals for TOEFL in China (College English Curriculum Requirements, 2007).

However, when language learners were given the chance to apply the target language, the large disparity would be found in foreign language speaking frequency. Some language learners would pursue every opportunity to speak in the FL on every occasion, conversely, others prefer to zip their mouth.

Grounded on the study of MacIntyre, Dörnyei, Clément, and Noels (1998), WTC in context of L2 is defined as a willingness to take part in a conversation at a specific time point with one or more particular individuals, using a target language. As an individual difference (ID) variable, WTC in English was proclaimed to boost L2 acquisition in EFL/ ESL (English as a Second Language) context (MacIntyre et al., 1998). WTC explicates the difference of EFL learners' inclination to communicate using an FL and widely captured increasing attention by many researchers in the recent two decades (Cao, 2014; Khajavy, MacIntyre, \& Barabadi, 2018; Peng, 2012, 2019). In the pedagogical domain, the research into L2 WTC is of high importance given its potential interpretation for learners' communication involvement and communicative psychology inside the classroom. As was explicitly contended by MacIntyre et al. (1998), the cultivating of WTC should be the decisive purpose of FL instruction.

\subsection{Problem Statement}

Firstly, despite this, the WTC level for Chinese EFL learners is still relatively low (Wei, Gao, \& Wang, 2019; You \& Dörnyei, 2014).

In the context of China, the FL teaching is exam-oriented without a test of oral English exam. Students usually suspect the significance of "talking" inside the classroom. Because only passing the College English Test (CET) is the major concern for their FL learning. They only focus on reading, listening, writing, and translation and ignore speaking in FL learning. Chinese EFL students often inactively act in oral interaction inside the FL classroom. It is not surprising that such non-involvement and silence deeply depressed body of Chinese EFL teachers. Moreover, this is also not aligned with the TEFL reform in China (Jiang \& Dewaele, 2019; Zhou, 2015).

Secondly, despite FL anxiety has been explored to exert a major influence on WTC, the impact of positive emotions on WTC remains less examined. And contrast with the influence of emotions on achievement has been broadly investigated in the common educational field (Kwon, Kupzyk, \& Benton, 2018; Raccanello, Hall, \& Burro, 2018; Xu, Du, Liu, \& Huang, 2019), however, emotions into FL research have been rarely studied (Dewaele \& MacIntyre, 2014; Dewaele, Witney, Saito, \& Dewaele, 2017).

Dörnyei and Ryan (2015) advocated more research attention on emotions in SLA. They argued that Emotions and feelings have been highly neglected by the SLA literature, though they place a huge role in all people's life. Dörnyei and Ryan (2015) explicitly proclaimed that positive emotions were highly suggested to be studied concurrently with negative emotions in research into SLA.

Furthermore, positive psychology (PosPsy) has captured greater research attention in the field of SLA in the past five years (Dewaele \& Li, 2018; Dewaele \& Li, 2020). A call for a systematic view of a wider scope of emotions including positive emotions of EFL learners has been made (Macintyre \& Gregersen, 2012; Saito, Dewaele, Abe, \& In'nami, 2018). Last but not least, MacIntyre and Mercer (2014) contended that without clear consideration of positive emotions, models of the communication process are half-finished. Thus, a gap existed for a holistic view of the role of positive emotions, in particular, enjoyment into WTC in English research seemed to be found.

\subsection{Research Objectives}

This study aims to investigate EFL learners' view on their level of FLE and WTC in English in normal universities in Shandong Province, China. The research objectives are as below:

1. To analyze the level of WTC in English (endogenous variable) in normal universities in Shandong Province of China.

2. To analyze the level of FLE (exogenous variable) in normal universities in Shandong Province of China.

3. To examine the relation between WTC in English and FLE in normal universities in Shandong Province of China.

4. To validate which dimensions of the FLE are the significant predictors of WTC in English in normal universities in Shandong Province, China.

5. To assess if the proposed structural model incorporating WTC in English and FLE fit with the data gathered from EFL learners in normal universities in Shandong Province, China.

\subsection{Conceptual Framework}

This study attempted to examine WTC in English as the dependent variable in relation to FLE as the independent 
variable. The creation of the conceptual framework for this current study was grounded on Maslow's (1954) and Seligman \& Csikszentmihalyi's (2000) the Positive Psychology theory that proclaimed the positive traits are conducive to human beings' success, self-actualization, and satisfaction. This was further developed by Broaden-and-Build Theory that argued that positive emotions perform a distinctive role in learning. Positive emotions can broaden people's attentional span, empowering them to build resources for the upcoming future. Positive emotion makes play and exploration easy, which is correlated with inspiration in problem-solving and an enlarged perceptual field (Dewaele \& Li, 2020; Fredrickson, 2013). Thus, as applied to the current study, positive emotions such as FLE may have the potential to influence on FL students' achievement and interactive communication performance inside the classroom.

Thus, drawing from a PosPsy perspective, this study attempts to examine the relationship between FLE and WTC in English. The conceptual framework of the current study is shown in Figure 1.

In the current framework, the endogenous variable, WTC in English consists of two dimensions based on Peng and Woodrow's model (2010). Operationalization for each dimension is shown as follow:

1. WTC in form-focused activities captures WTC when FL learners are involving in activities where specific linguistic traits (to illustrate, grammar, vocabulary, and pronunciation) are accentuated. For example, asking the peer the pronunciation of words;

2. WTC in meaning-focused activities refers to WTC when FL learners are engaging in activities in which message-exchanging is highlighted. For instance, giving a self-introduction in front of classmates.

The exogenous variable, FLE is comprised of three dimensions grounded on The Chinese Version of Foreign Language Enjoyment Scale (CFLES) adapted in Li, Jiang, \& Dewaele's study (2018). Each dimension is operationally conceptualized as below:

1. FLE-Private correlates the personal pleasure emerging from pushing one's limits or individual progress, excellent performance, and exciting experience in FL learning process. For instance, the realization of achieving progress in writing skill;

2. FLE-Teacher captures students' pleasure concerning EFL teachers' inspiring and supporting attitude towards them in EFL learning. For instance, EFL teachers' high praise to the student.

3. FLE-Atmosphere means how students understand the positive atmosphere created inside the EFL classroom through group activities. For example, enjoyable role-play using FL with group mates.
EXOGENEOUS VARIABLE

Foreign Language Enjoyment: (CFLES)

1. FLE-Private

2. FLE-Teacher

3. FLE-Atmosphere
ENDOGENEOUS VARIABLE

Willingness to Communicate in

English:

(Peng's model, 2010)

1. Willingness to communicate in form-focused activities

2. Willingness to communicate in meaning-focused activities

Figure 1. Conceptual framework of this study 


\section{Literature Review}

Lake (2013) is one of the first batch researchers who explicitly drew the PosPsy perspective into SLA research (MacIntyre \& Mercer, 2014), although some variables of PosPsy (i.e. achievement emotions, and emotional intelligence) had been studied in FL learning setting before this study (Li, 2019; Raccanello et al., 2018). In his study, Lake verified that positive L2 Self, as the mediator on the relationship between positive self and motivational variables (like "self-efficiency"), influenced FL learning in the Japanese context. This seminal study not only formerly introduced the PosPsy constructs into the field of SLA but also provided a research paradigm for PosPsy evidence studies in the domain of SLA. This study also indicated the formal generation of PosPsySLA (Li \& Jiang, 2017).

Gabryś-Barker and Gałajda (2016), and MacIntyre, Gregersen, and Mercer (2016) provided a body of case studies for PosPsy theories, evidence research, and intervention practices in two academic collections. Around the "three pillars" of PosPsy proposed by Seligman and Csikszentmihalyi (2000), these two collections examined a variety of psychological-social variables under the perspective of PosPsy. More specifically, Khajavy et al. (2016) investigated directional motivation flow, empathy, affection, past self, persistence, positive L2 Self, social capital, hope, flow experience and expectation. Gabryś-Barker and Gałajda (2016) discussed participation, emotional intelligence, well-being, individual strengthens, responsibility, positive emotions, positive classroom environment, self-esteem, expectation, personality, and enjoyment. Those works of literature jointly responded to the doubt placed on PosPsy for lack of sufficient empirical studies. Also, PosPsy thus proved that it enables to provide a maturing, scientific, and systematic view towards SLA (Li \& Jiang, 2017).

Literature has revealed that students experience a large scale of negative and positive emotions (MacIntyre \& Vincze, 2017). But based on Fredrickson's (Fredrickson, 2001) the broaden-and-build theory, positive emotion has been shown a qualitative difference with negative emotions (Macintyre \& Gregersen, 2012). Compared with negative emotion, positive emotion attempts to broaden persons' attentional focus instead of narrowing the range of attention (Fredrickson, 2013).

Anxiety is one of the most-analyzed negative emotions among negative emotions both in the area of education and FL literature

(Dewaele \& MacIntyre, 2014; Dewaele et al., 2017). Anxiety was also found to be an inhibitor towards the creation of WTC (Khajavy et al., 2016; Khajavy et al., 2018).

However, compared with what we understood about anxiety, the effect of positive emotions towards FL learning in class remains less-known. Kang (2005) reported excitement, responsibility, and security are psychological predictors of WTC. Cao (2014) proclaimed that along with negative emotions, positive emotions also influence the students' interaction performance inside the classroom; enjoyment was confirmed using a qualitative approach to affect students' WTC.

More recently, (MacIntyre \& Vincze, 2017) emphasized without the consideration of positive emotions, and merely with the negative emotions, an integral and systematic understanding for the role in FL learning could not able to be obtained. Align with the movement for employing PosPsy into FL learning, Dewaele et al. (2017) and Dewaele and $\mathrm{Li}$ (2020) called for enlarging the highlight exclusive on negative emotions and strongly suggested considering FL learners' positive emotions into FL research.

What's more, compared with negative emotions, positive emotions were found to have a higher level among FL learners in a global investigation (Dewaele, Macintyre, Boudreau, \& Dewaele, 2016; Dewaele \& MacIntyre, 2014). And practitioners can have a noticeable influence on FL students' enjoyment and merely a weaker influence on their language anxiety. Furthermore, enjoyment seems to be more relevant with FL learning which features possible enjoyable interactive relationships, and numerous group activities in class, while, fostering interpersonal relations and feeling of achievement obtained in making progress were pointed out to be the source of enjoyment in the FL classroom (Dewaele \& MacIntyre, 2014).

The first study which explicitly integrated WTC and enjoyment is conducted by (Khajavy et al., 2018).In that study, enjoyment was found to have a stronger influential effect on enhancing WTC than foreign language anxiety among Iranian secondary school students. However, enjoyment appears to be more popular existed than anxiety in the FL classroom, which is an essential platform for EFL learners (Zhou, 2015). Thus, grounded on the literature aforementioned, the impact of positive emotions, in particular, FLE on WTC inside the classroom in EFL contexts appears to be a gap needed to be further filled.

\section{Methodology}

\subsection{Research Design}

This study sought to explore the relationship between FLE as the exogenous variable (independent variable) with L2 WTC in English as the endogenous variable (dependent variable). In so doing, quantitative research approach was employed to account for how one variable influence another (Creswell \& Guetterman, 2019), in other words, to establish a path between constructs (Fraenkel, Wallen, \& Hyun, 2011). In this quantitative study, a survey method was employed and the numerical data were gathered through the administration of a questionnaire adopted. Two self-administered and cross-sectional questionnaires were 
applied as the data collection instrument in this research design.

\subsection{Contexts and Participants}

A total of 128 EFL undergraduate students (Female $=77$, $60.2 \%$; Male $=51,39.8 \%$ ) recruited from one normal university in middle eastern of Shandong province in China participated in this survey (According to Tabachnick and Fidell (2019), SEM could be analyzed using 60 observations, though larger sample size is better). All respondents stood for a diverse of non-English-majors (e.g., Cultural Industry Management, Finance, and News Editing) who were prepared to become teachers after graduation. All the participants were sophomores $(n=57,44.5 \%)$ or freshmen $(n=71,55 \%)$. Seniors and juniors were not enlisted since only freshmen and sophomores are asked to have college English as a compulsory course in China. To avoid possible mistakes, students majoring in English were not involved considering that the disparity in the English courses attended and the predictable FL learning results between them.

\subsection{Instrument}

A set of questionnaires were adopted by the authors to collect the data information acquired for this research. The instrument was comprised of three parts, including participant demographic information, the scale of FLE, and WTC in English. EFL Student demographic information involved age, gender, hometown, grade, major.

The scale of WTC in English referred to the study conducted by Peng and Woodrow (2010). Two dimensions of WTC in English were assessed in the questionnaire, including ( iWTC in meaning-focused activities, and (ii ) WTC in form-focused activities. This scale was originally adapted from Weaver's (2005) scale of WTC in specific speaking situations, which evaluates how much the degree participants are inclined to speak using an FL in certain classroom situations. In this study, the 10 items underlying L2 WTC in English were self-reported using a standard 6-point Likert scale, scoping from "definitely willing" to "definitely not willing". High score respondent would be viewed as having a high level of WTC.

The CFLES with 11 items referred to Li et al. (2018) was utilized to evaluate FLE in this study. This scale contains three sub-scales which are correspondent to the three factors of FLE in the context of China, including FLE-Teacher, FLE-Private, and FLE-Atmosphere. These three dimensions describe ( iChinese EFL students' FLE experiences correlating to the supportive and encouraging attitudes from teachers; (ii ) students' enjoyable feelings sourcing from their interest, self-accomplishments, and fun in process of EFL learning; and (iii) the positive group or atmosphere for EFL learning (Li et al., 2018). The CFLES was previously adapted from FLE Scale (Dewaele \& MacIntyre, 2014) and was verified as taking high psychometric properties based on its high validity and reliability (Li et al., 2018). The CFLES is rated on a standard 5-point Likert scale, ranging from 1 "strongly disagree" to 5 "strongly agree". High score participants would be seen as having a high tone of FLE.

The instrument in this study was examined with 59 normal EFL undergraduates from Jinan, China as a pilot study. Employing the SPSS (Statistical Packages for the Social Sciences) for version 25.0, data gathered were addressed for the test of internal consistency. Utilizing the Cronbach's alpha value approach, the analysis results reported that the Cronbach's alpha value for each dimension of L2 WTC in English was .863 and .899, and for dimensions underlying FLE were in the scope of .826-.888. This indicated that this instrument achieved reliability at an acceptable level ( $\alpha>$.65) (Chua, 2013).

In the main study, prior to the model fitness test, the convergent and discriminant validity were achieved (all factor loadings of each items of WTC and FLE were between .586 and .949; CFI of each dimensions were $>.90$, RMSEA $<.08, \quad \mathrm{CMIN} / \mathrm{DF}<5.0$; all the correlational coefficients for each items were in the range of .37- .83). And factor analysis value of each indicator, AVE, CR, Cronbach's alpha was also established at corresponding acceptable levels.

\subsection{Analysis of Data}

Quantitative analysis methods were employed to address the numerical data collected using SPSS version 25 and AMOS (Analysis of Moment Structures) version 23. To answer the research questions proposed, both inferential and descriptive statistical methods were used through SPSS. Specifically, to address the first two research questions, the descriptive statistical method involving mean and standard deviation (SD) were applied. The global composite means for each one of the dimensions were incorporated into three layers with equal interval, where each layer is respectively interpreted as low, medium, or high. To identify the correlation between WTC in English and FLE, the Pearson product-moment correlation test under inferential statistical method was conducted, while the stepwise multiple regression analysis was executed to examine which dimensions underlying FLE account for the changes in WTC in English. At length, the SEM procedure was performed to verify whether the data gathered fit with the assumptive model involving WTC in English and FLE for the research sample using AMOS. 


\section{Findings}

The analysis results of this research on each of the research questions were showed in this section.

RQ 1: What are the levels of WTC in English in normal universities in Shandong province, China?

Descriptive statistical methods were employed to address the numerical data gathered from 128 students in normal universities in Shandong Province, China. The analysis results yielded were presented in Table 1.

Table 1. Standard Deviation, Mean and the Level of WTC in English $(\mathrm{N}=128)$

\begin{tabular}{lccc}
\hline Dimension & Mean & SD & Level \\
\hline 1) WTC in meaning-focused activities & 3.95 & 1.07 & Medium \\
2) WTC in form-focused activities & 4.40 & 1.20 & High \\
Overall & 4.13 & 1.01 & High \\
\hline
\end{tabular}

Note: $\mathrm{WTC}=$ Willingness to communicate in English; $\mathrm{SD}=$ standard deviation

According to Table 1, the global mean for WTC in English was 4.13. This could be explained as a high level of WTC in English for students in normal universities in Shandong Province of China. Regarding each dimension underlying WTC in English, WTC in meaning-focused activities showed a medium level of mean, whereas the other dimension, namely WTC in form-focused activities demonstrated a high level of mean.

RQ 2: What are the levels of FLE in normal universities in Shandong province, China?

The analysis results of descriptive statistics for the level of FLE were presented in Table 2.

Table 2. Mean, Standard Deviation and the Level of FLE (N=128)

\begin{tabular}{lccc}
\hline \multicolumn{1}{c}{ Dimension } & Mean & $\begin{array}{c}\text { Standard } \\
\text { Deviation }\end{array}$ & Level \\
\hline $\begin{array}{l}\text { 1) Foreign Language } \\
\text { Enjoyment-Private } \\
\text { 2) Foreign Language }\end{array}$ & 3.24 & 0.97 & Medium \\
$\begin{array}{l}\text { Enjoyment-Teacher } \\
\text { 3) Foreign Language }\end{array}$ & 4.09 & 0.88 & High \\
$\begin{array}{l}\text { Enjoyment-Atmosphere } \\
\quad \text { Overall }\end{array}$ & 3.09 & 1.03 & Medium \\
\hline
\end{tabular}

As presented in Table 2, the global mean for FLE was 3.43, which could be explained as a high level of FLE in normal universities in Shandong Province of China. Concerning each dimension of FLE, the analysis outputs for each dimension of FLE demonstrated that two out of the three FLE dimensions take lower mean than the global mean. These dimensions are FLE-Private and FLE-Atmosphere. Whereas the other dimension, FLE-Teacher showed a higher mean than the global mean of FLE. Nevertheless, all the three dimensions underlying FLE have means that are explicated as high level, which implied the participants rated themselves as taking high level for all the three FLE dimensions in normal universities in Shandong province, China.

RQ 3: Is there a significant interrelationship between FLE and WTC in English in normal universities in Shandong Province of China?

The Pearson product-moment correlation test was conducted to analyze the relations between WTC in English and FLE. The analysis outputs were reported in Table 3 as below.

Table 3. Pearson Product-Moment Correlation Analysis between WTC in English and FLE $(\mathrm{N}=128)$

\begin{tabular}{ccc}
\hline \multicolumn{2}{c}{ Variable } & $\begin{array}{c}\text { Willingness to } \\
\text { communicate in } \\
\text { English }\end{array}$ \\
\hline $\begin{array}{c}\text { Foreign Language } \\
\text { Enjoyment }\end{array}$ & $\begin{array}{c}\text { Pearson } \\
\text { Correlation }\end{array}$ & $.63^{* *}$ \\
& Sig. (2-tailed) & .00 \\
$\mathrm{~N}$ & 128
\end{tabular}

Note: **. Correlation is significant at the 0.01 level (2-tailed).

Table 3 indicated that for the research sample $(n=128)$, there was a statistically significant positive correlation that was moderately strong $(\gamma=.63, \rho<.01)$ between WTC in English and FLE.

RQ 4: Which dimensions of the FLE are the significant predictors of WTC in English in normal universities in Shandong Province of China?

The analysis outputs of inferential statistics through the multiple regression analysis obtained were showed in Table 4 as follows.

Table 4. Multiple Regression (Stepwise) on FLE to WTC in English ( $\mathrm{N}=128)$

\begin{tabular}{ccccccc}
\hline Variable & (Unstad.) & (Stand.) & Sig & B & Contribution \\
$(\%)$ & $\mathrm{B}$ & .630 & .604 & 8.504 & .000 & .360 \\
\hline Foreign Language Enjoyment-Private & .321 & .280 & 3.595 & .000 & .415 \\
\hline Foreign Language Enjoyment-Teacher & 1.238 & & 3.675 & .000 \\
\hline Constant & & 5.5 & \\
\hline
\end{tabular}


The outputs of multiple regression analysis showed in Table 4 implied that the prediction model comprised two out of the three predictors, including FLE-Private $(\beta=.604$, $\rho=.000)$, and FLE-Teacher $(\beta=.280, \rho=.000)$. FLE-Private dimension (model 1 ) was reported to account for $36.0 \%$ of the variance in WTC in English $\left(\mathrm{R}^{2}=.360\right)$, while the combination of FLE-Private and FLE-Teacher dimension (model 2) contributed $41.5 \%$ of the variance in WTC in English $\left(\mathrm{R}^{2}=.415\right)$. Informed by the benchmark range of effect sizes studied by Cohen (1988), this model indicated a large effect size on WTC in English.

The dominant predictor for WTC in English is FLE-Private dimension of FLE ( $\beta=.604, t=8.504$ and $\rho$ $=.000$ ). The t-test output was a significant level of $\rho<.05$ with the $\mathrm{R}^{2}=.360$, which revealed that FLE-Private dimension contributes $36.0 \%$ of the variance in WTC in English. Grounded on the standardized $\beta$ value, when the FLE-Private dimension of the FLE enhanced by 1 unit of SD, WTC in English would be boosted by .604 unit of SD.

The second predictor for WTC in English is FLE-Teacher dimension of FLE ( $\beta=.280, t=3.595$ and $\rho$ $=.000$ ). This dimension separately contributed $5.5 \%$ of the variance in WTC in English. The t-test output was significant at the significant level $(\rho<.05)$ with the combined $\mathrm{R}^{2}=.415$, which revealed that these two dimensions, namely FLE-Private and FLE-Teacher dimension jointly contributed $41.5 \%$ of the variance in WTC in English. Grounded on the standardized $\beta$ value, when the FLE-Teacher dimension of the FLE boosted by 1 unit of SD, WTC in English would enhance by .280 unit of
SD.

Table 5. Stepwise Multiple Regression Analysis: ANOVA

\begin{tabular}{cccccc}
\hline & $\begin{array}{c}\text { Sum of } \\
\text { Squares }\end{array}$ & df & $\begin{array}{c}\text { Mean } \\
\text { Square }\end{array}$ & $F$ & Sig. \\
\hline Regression & 54.930 & 2 & 27.465 & 46.044 & .000 \\
Residual & 74.562 & 125 & .596 & & \\
Total & 129.492 & 127 & & & \\
\hline
\end{tabular}

Note: ANOVA= Analysis of Variance

According to Table 5, the ANOVA result revealed that FLE-Private and FLE-Teacher dimension have a significant positive predictive impact on WTC in English $(\mathrm{F}=46.044, \rho=.000)$ at a significance level of $\mathrm{p}<.05$. This multiple regression analysis results also indicated that the combination of FLE, FLE-Private and FLE-Teacher dimension jointly contributed for $41.5 \%$ of the variance in WTC in English. This denoted that as much as 58.5\% of the variance in WTC in English were not able to be predicted by FLE as it could be brought out by other constructs (variables) not analyzed in this research.

RQ 5: Does the data gathered fit with the proposed model of WTC in English and FLE in normal universities in Shandong province of China?

Informed by Byrne (2016), the essential target for the model-testing technique was to testify the model fit between the proposed model and the data for the sample. The results gained by SEM statistic were presented in the below Figure 2.

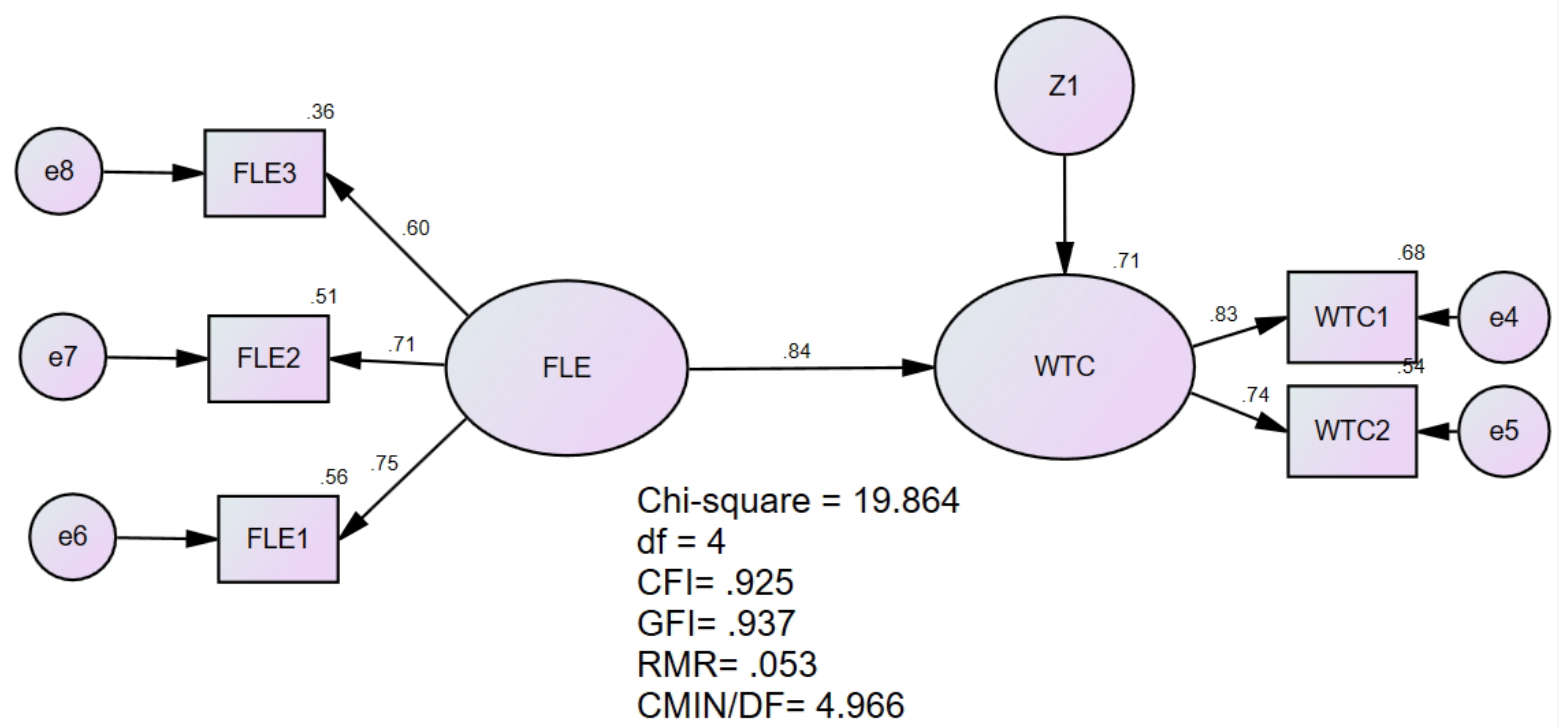

Note: FLE=Foreign Language Enjoyment; WTC=Willingness to Communicate in English

Figure 2. The Proposed Structural Model 
According to the SEM structural model shown in Figure 2 , it was implied that all the fitness indexes achieved were at an acceptable level with CFI $>.90$, GFI $>.90$, RMR $<.10$, Ratio Chisq/df $<5$. This revealed that the goodness-of-fit (GOF) between this structural model with the data self-reported from Shandong normal universities of China. The standardized $\beta$ value for FLE $\rightarrow$ WTC in English is .84, denoting that when FLE enhanced by 1 SD, WTC in English would correspondingly increase by $.84 \mathrm{SD}$. The squared multiple correlation $\mathrm{R}^{2}$ value for FLE and WTC in English is .71, which indicated that FLE could predicate 71\% of the variance in WTC in English. That is to say, there were as few as $29 \%$ of the variance in WTC were unable to be predicted by FLE as this may be aroused by other factors (constructs) not validated in this present study.

\section{Discussion}

The analysis result of the Pearson product-moment correlation test revealed that there was a statistically significant positive correlation which was moderately strong between FLE and WTC in English. The positive correlation implied that if the EFL students take a higher level of FLE, the level of WTC in English would be boosted as well. Thus, FLE was verified to be one of the predictors impacting on WTC in English. The relation that exists between WTC in English and FLE can be buttressed by the control-value theory studied by Pekrun (2006) and Pekrun, Frenzel, Götz, and Perry (2007) and Broaden-and-Build theory proposed by Fredrickson (2001) showing that emotions are influential factors toward FL learning performance, and the influence exerted from positive emotions and negative emotions are essentially different. This relationship between WTC and FLE aligns with the empirical study findings carried out by Cao (2014), and Khajavy et al. (2018), who found that students those enjoy FL learning tend to be readier to communicate using FL.

Also, through the stepwise multiple regression test, it was showed that FLE-Private and FLE-Teacher are the two FLE dimensions that are statistically significant antecedents of WTC in English for tertiary EFL students in normal of Shandong, China. This finding indicates that the level of WTC in English would be enhanced when FL students perceived that their progress, interesting experience, outstanding performance were achieved in FL learning and noticed that FL teachers' inspiring and supporting attitude towards them inside FL classroom. This was in line with Cao' study (2011, 2014)who contended that alongside with a range of both the positive emotions and negative emotions, including boredom, frustration, disappointment, and anger, enjoyment found to be the individual influencing factors for EFL students' WTC in class.

The data analysis implied that the hypothesized structural model attains the fitness indexes at a required level. This revealed that the hypothesized structural model matched well with the data gathered from the EFL freshmen and sophomores in Shandong normal universities of China. Hence, the structural model as presented in Figure 2 was well established.

\section{Conclusion}

Fostering students' WTC and empowering them to speak using FL is one of the predominant objectives of EFL teaching across the globe (MacIntyre et al., 1998). Cultivating the communicative competence of learners has been emphasized by the novel evolution of EFL teaching. There is an urging and extensive need for educational practitioners to enhance the students' WTC to increase their actual L2 use. In China, English subject is one of the mandatory subjects for all sophomores and freshmen. Educational policy-makers also emphasize the cultivation of English language learners' interactive communication skills (College English Curriculum Requirements, 2007).

This current study provided evidence for the predictive role of FLE towards WTC in English in context of China through drawing a PosPsy perspective and establishing a structural model integrating both of them using SEM technique with AMOS 23.0. Furthermore, implications also are obtained for Chinese EFL teachers that building a positive and joyful FL classroom is conducive for increasing FL learners' level of WTC.

Specifically, the structural model integrating L2 WTC and FLE was consistent with Khajavy et al. (2018) who argued that along with foreign language anxiety, FL learners' shared sense of an enjoyable classroom was found to foster WTC in English both in individual and classroom level in the Iranian context. Consequently, to enhance FL students' WTC in English, additional emphasis should be given to the improvement of their FLE as per the two dimensions which place a higher effect on WTC that yielded from the findings of the current study.

\section{REFERENCES}

[1] Byrne, B. M. (2016). Structural Equation Modeling With AMOS: Basic Concepts, Applications, and Programming (3rd edition). New York: Taylor \& Francis Group.

[2] Cao, Y. (2011). Investigating situational willingness to communicate within second language classrooms from an ecological perspective. System, 39(4), 468-479. doi:10.1016/j.system.2011.10.016

[3] Cao, Y. (2014). A sociocognitive perspective on second language classroom willingness to communicate. TESOL Quarterly, 48(4), 789-814. doi:10.1002/tesq.155

[4] Cetinkaya, Y. B. (2005). Turkish college students' 
willingness to communicate in English as a foreign language. (Electronic Thesis or Dissertation), Columbus, OH: Ohio State University.

[5] Chua, Y. P. (2013). Mastering Research Statistics. Malaysia: McGraw-Hill Education.

[6] Cohen, J. (1988). Statistical Power Analysis for the Bahavioral Sciences (Second ed.). Hillsdale, New Jersey: Lawrence Erlbaum Associates, Inc.

[7] College English Curriculum Requirements. (2007). Retrieved from http://www.moe.gov.cn/publicfiles/business /htmlfiles/moe/cmsmedia/image//UserFiles/File/2008/05/06 /2008050611/2008050611_163068.doc.

[8] Creswell, J., \& Guetterman, T. (2019). Educational research: Planning, conducting, and evaluating quantitative and qualitative research (6th Edition ed.). New York, US: Pearson.

[9] Dörnyei, Z., \& Ryan, S. (2015). The Psychology of the Language Learner Revisited. New York: Routledge.

[10] Dewaele, \& Li, C. (2018). Editorial of the special Issue 'Emotions in SLA'. Studies in Second Language Learning and Teaching, 8(1), 15-19.

[11] Dewaele, \& Li, C. (2020). Emotions in Second Language Acquisition: A critical review and research agenda.

[12] Dewaele, Macintyre, P., Boudreau, C., \& Dewaele, L. (2016). Do Girls Have All the Fun? Anxiety and Enjoyment in the Foreign Language Classroom. Theory and Practice of Second Language Acquisition, 2, 41-63.

[13] Dewaele, \& MacIntyre, P. D. (2014). The two faces of Janus? Anxiety and enjoyment in the foreign language classroom. Studies in Second Language Learning and Teaching, 2, 237-274. doi:10.14746/ssllt.2014.4.2.5

[14] Dewaele, Witney, J., Saito, K., \& Dewaele, L. (2017). Foreign language enjoyment and anxiety: The effect of teacher and learner variables. Language Teaching Research, 22(6), 676-697. doi:10.1177/1362168817692161

[15] Fraenkel, J. R., Wallen, N. E., \& Hyun, H. H. (2011). How to design and evaluate research in education: New York: McGraw-Hill.

[16] Fredrickson. (2001). The role of positive emotions in positive psychology: The broaden-and-build theory of positive emotions. American Psychologist, 56(3), 218.

[17] Fredrickson. (2013). Updated thinking on positivity ratios. American Psychologist, 68(9), 814-822. doi:10.1037/a0033584

[18] Gabryś-Barker, D., \& Gałajda, D. (2016). Positive psychology perspectives on foreign language learning and teaching. Gewerbestrasse: Springer.

[19] Jiang, Y., \& Dewaele, J.-M. (2019). How unique is the foreign language classroom enjoyment and anxiety of Chinese EFL learners? System, 82, 13-25. doi:https://doi.org/10.1016/j.system.2019.02.017

[20] Kang, S.-J. (2005). Dynamic emergence of situational willingness to communicate in a second language. System, 33(2), 277-292. doi:10.1016/j.system.2004.10.004
[21] Khajavy, G. H., Ghonsooly, B., Hosseini Fatemi, A., \& Choi, C. W. (2016). Willingness to communicate in English: A microsystem model in the Iranian EFL classroom context. TESOL Quarterly, 50(1), 154-180. doi:10.1002/tesq.204

[22] Khajavy, G. H., MacIntyre, P. D., \& Barabadi, E. (2018). Role of the emotions and classroom environment in willingness to communicate: Applying doubly latent multilevel analysis in second language acquisition research. Studies in Second Language Acquisition, 40(3), 605-624. doi:10.1017/s0272263117000304

[23] Kwon, K., Kupzyk, K., \& Benton, A. (2018). Negative emotionality, emotion regulation, and achievement: Cross-lagged relations and mediation of academic engagement. Learning and Individual Differences, 67, 33-40. doi:https://doi.org/10.1016/j.lindif.2018.07.004

[24] Lake, J. (2013). Positive L2 self: Linking positive psychology with L2 motivation. In M. T. Apple, D. D. Silva, \& T. Fellner (Eds.), Language learning motivation in Japan (pp. 225-244). Bristol: Channel View Publications.

[25] Li, C. (2019). A Positive Psychology perspective on Chinese EFL students' trait emotional intelligence, foreign language enjoyment and EFL learning achievement. Journal of Multilingual and Multicultural Development, 1-18. doi:10.1080/01434632.2019.1614187

[26] Li, C., \& Jiang, G. (2017). Positive psychology perspectives on foreign language learning and teaching. International Journal of Bilingual Education and Bilingualism, 1-3. doi:10.1080/13670050.2017.1350279

[27] Li, C., Jiang, G., \& Dewaele, J.-M. (2018). Understanding Chinese high school students' Foreign Language Enjoyment: Validation of the Chinese version of the Foreign Language Enjoyment scale. System, 76, 183-196. doi:10.1016/j.system.2018.06.004

[28] Long, M. H. (1996). The role of the linguistic environment in second language acquisition. In W. C. Ritchie \& T. K. Bahtia (Eds.), Handbook of Second Language Acquisition (pp. 412-468). New York, NY: Academic Press.

[29] MacIntyre, \& Charos, C. (1996). Personality, attitudes, and affect as predictors of second language communication. Journal of Language and Social Psychology, 15(1), 3-26. doi:10.1177/0261927x960151001

[30] MacIntyre, Dörnyei, Z., Clément, R., \& Noels, K. A. (1998). Conceptualizing willingness to communicate in a L2: A situational model of L2 confidence and affiliation. The Modern Language Journal, 82(4), 545-562. doi:10.1111/j.1540-4781.1998.tb05543.x

[31] Macintyre, \& Gregersen, T. (2012). Emotions that facilitate language learning: The positive-broadening power of the imagination. Studies in Second Language Learning and Teaching, 2, 193-213. doi:10.14746/ssllt.2012.2.2.4

[32] MacIntyre, Gregersen, T., \& Mercer, S. (2016). Positive psychology in SLA. Bristol: Multilingual Matters.

[33] MacIntyre, \& Mercer, S. (2014). Introducing positive psychology to SLA. Studies in Second Language Learning and Teaching, 2, 153-172. doi:10.14746/ssllt.2014.4.2.2

[34] MacIntyre, \& Vincze, L. (2017). Positive and negative emotions underlie motivation for L2 learning. Studies in 
Second Language Learning and Teaching, 7(1), 61. doi:10.14746/ssllt.2017.7.1.4

[35] Maslow. (1954). Motivation and personality. New York: Harper \& Row.

[36] Pekrun, R. (2006). The control-value theory of achievement emotions: Assumptions, corollaries, and implications for educational research and practice. Educational Psychology Review, 18(4), 315-341. doi:10.1007/s10648-006-9029-9

[37] Pekrun, R., Frenzel, A., Götz, T., \& Perry, R. (2007). The control-value theory of achievement emotions: An integrative approach to emotions in education. Emotion in education, 13-36.

[38] Peng, J.-E. (2012). Towards an ecological understanding of willingness to communicate in EFL classrooms in China. System, 40(2), 203-213. doi:10.1016/j.system.2012.02.002

[39] Peng, J.-E. (2019). Understanding willingness to communicate as embedded in classroom multimodal affordances: Evidence from interdisciplinary perspectives. Linguistics and Education, 51, 59-68. doi:10.1016/j.linged.2019.04.006

[40] Peng, J.-E., \& Woodrow, L. (2010). Willingness to communicate in English: A model in the Chinese EFL classroom context. Language Learning, 60(4), 834-876. doi:10.1111/j.1467-9922.2010.00576.x

[41] Raccanello, D., Hall, R., \& Burro, R. (2018). Salience of primary and secondary school students' achievement emotions and perceived antecedents: Interviews on literacy and mathematics domains. Learning and Individual Differences, 65 , 65-79. doi:https://doi.org/10.1016/j.lindif.2018.05.015

[42] Saito, K., Dewaele, J.-M., Abe, M., \& In'nami, Y. (2018). Motivation, emotion, learning experience, and second language comprehensibility development in classroom settings: a cross-sectional and longitudinal study. Language Learning, 68(3), 709-743. doi:10.1111/lang.12297

[43] Seligman, M. E. P., \& Csikszentmihalyi, M. (2000). Positive psychology: An introduction. American Psychologist, 55(1), 5-14. doi:10.1037/0003-066x.55.1.5

[44] Swain, M., \& Lapkin, S. (1995). Problems in output and the cognitive processes they generate: A step towards second language learning. Applied Linguistics, 16, 371-391. doi:10.1093/applin/16.3.371

[45] Tabachnick, B. G., \& Fidell, L. S. (2019). Using Multivariate Statistics (7th Edition ed.). Boston, MA: Pearson Education Inc.

[46] Weaver, C. (2005). Using the Rasch model to develop a measure of second language learners' willingness to communicate within a language classroom. Journal of applied measurement, 6(4), 396-415.

[47] Wei, H., Gao, K., \& Wang, W. (2019). Understanding the relationship between grit and foreign language performance among middle school students: The roles of foreign language enjoyment and classroom environment. Frontiers in Psychology, 10(1508). doi:10.3389/fpsyg.2019.01508

[48] Xu, J., Du, J., Liu, F., \& Huang, B. (2019). Emotion regulation, homework completion, and math achievement: Testing models of reciprocal effects. Contemporary Educational Psychology, 59, 101810. doi:https://doi.org/10.1016/j.cedpsych.2019.101810

[49] You, C., \& Dörnyei, Z. (2014). Language learning motivation in China: Results of a large-scale stratified survey. Applied Linguistics, 37(4), 495-519. doi:10.1093/applin/amu046

[50] Zhou, N. (2015). Oral participation in EFL classroom: Perspectives from the administrator, teachers and learners at a Chinese university. System, 53, 35-46. doi:https://doi.org/10.1016/j.system.2015.06.007 